\section{Reducing retail supply chain costs of product returns using digital product fitting}

Retail supply chain costs of product returns

Emmelie Gustafsson and Patrik Jonsson

Department of Technology Management and Economics, Chalmers University of Technology, Gothenburg, Sweden, and Jan Holmström

Department of Industrial Engineering and Management, Aalto University, Helsinki, Finland

\begin{abstract}
Purpose - This paper investigate how fit uncertainty impacts product return costs in online retailing and how digital product fitting, a pre-sales fitting practice, can reduce fit uncertainty.

Design/methodology/approach - The paper analyzes the current performance of a retailer's e-commerce and return operations by estimating costs generated by product returns, including product handling costs, tiedup capital, inventory holding costs, transportation costs, and order-picking costs. The estimated costs were built on 2,229 return transactions from a Scandinavian fashion footwear retailer. A digital product fitting technology was tested with the retailer's products and resulted in estimations on how such technology could affect product returns.

Findings - The cost of a return is approximately $17 \%$ of the prime cost. The major cost elements are product handling costs and transportation costs, which together amount to $72 \%$ of the total costs. If well calibrated, the fitting technology can cut fit-related return costs by up to $80 \%$. The findings show how customers reacted to the fitting technology: it was unable to verify fit every time, but it serves as a useful and effective support tool for customers when placing orders.

Research limitations/implications - Virtual fit verification using digital product fitting is key to retailers to reduce fit-related returns. Digital product fitting using three-dimensional scanning is more appropriate for some products, but it is unsuitable for products that are difficult to measure and scan.

Originality/value - The paper contributes an empirical estimate of retail supply chain costs associated with fit uncertainty, as well as theoretical understanding of the role of pre-sales fit verification in avoiding product returns.
\end{abstract}

Keywords Product return costs, Retail supply chains, Product returns, Return reasons, Fit uncertainty,

3D scanning, Product recommendation system

Paper type Research paper

\section{Introduction}

Retail supply chains typically offer customers a multitude of product variants and models, especially online. For a customer to reach a purchase decision, it is critical for the seller to showcase the products as accurately as possible so that the product characteristics are clear to the customer and can be identified from among the available product supply (Weathers et al., 2007). Research shows that conveying accurate product descriptions is a key process for reducing returns (De Leeuw et al., 2016; Hjort et al., 2019) and counteracting increased reverse logistics costs, such as inventory holding costs and product handling costs (Rogers et al., 2002).

(C) Emmelie Gustafsson, Patrik Jonsson and Jan Holmström. Published by Emerald Publishing Limited. This article is published under the Creative Commons Attribution (CC BY 4.0) licence. Anyone may reproduce, distribute, translate and create derivative works of this article (for both commercial and noncommercial purposes), subject to full attribution to the original publication and authors. The full terms of this licence may be seen at http://creativecommons.org/licences/by/4.0/legalcode
International Journal of Physical Distribution \& Logistics Management Vol. 51 No. 8,2021 pp. $877-896$

Emerald Publishing Limited 0960-0035 DOI 10.1108/IJPDLM-10-2020-0334 
IJPDLM 51,8

A factor that directly increases product returns is fit uncertainty-i.e., when customers have trouble evaluating the fit of a product pre-purchase (Hong and Pavlou, 2014). Footwear and apparel products are goods that involve high fit uncertainty. These products are especially prone to high return rates when purchased online, since customers cannot physically try on the products before their purchase. Product fit uncertainty arises from a lack of product fit experience information and technology-enabled heuristics that indicate a match between product attributes and customer preferences (Hong and Pavlou, 2014).

To support customers ordering fit-dependent products online, retailers can apply different technologies to webshops to make fit more comprehensible for customers (Gustafsson et al., 2019; Miell et al., 2018); these range from the most basic size chart converter to more advanced technologies that provide virtual fit verification. However, while size charts are easy to implement, their accuracy is questionable. Research has proposed virtual try-ons and interactive trial rooms for customers to visualize fit (Liu et al., 2017; Misra and Arivazhagan, 2017), but these technologies may not represent fit realistically, as they often lack customer scanning data (Miell et al., 2018). More advanced technologies are implementation-heavier but are also more accurate and can provide fit verification (Gustafsson et al., 2019). Academically, previous research has investigated the influence of online customer reviews on product returns (Minnema et al., 2016), the effect of digital fitting tools on mitigating product returns (Gustafsson et al., 2019; Misra and Arivazhagan, 2017), the effect of return policy leniency on product returns (Janakiraman et al., 2016) and company practices for managing product returns (Hjort et al., 2019).

This paper investigates how fit uncertainty impacts product return costs in online retailing and how digital product fitting, a pre-sales fitting practice, can reduce fit uncertainty. Thus far, to the best of our knowledge, only Ketzenberg et al. (2020) have quantified costs associated with product returns, with a focus on customers abusing the terms of returns. They model costs from the perspective of profit losses but do not dive deeper into categories of costs that make up the profit loss. Our paper expands the cost aspect to include the categories of costs incurred by product returns. The context of our empirical study is returns in online shoe retail. We model the product returns costs of a Scandinavian ecommerce fashion shoe retailer that does not use fit uncertainty mitigation tools in its webshop. The cost categories are product handling, tied-up capital, inventory holding, transportation costs, and order picking. In addition, we test an existing digital product fitting technology on the retailer's products, observe how it reduces fit uncertainty for the retailer's products, and apply fit verification rates to the product return costs.

Our paper contributes to the literature on costs of product returns by quantifying the return costs associated with fit uncertainty. Furthermore, it contributes to understanding how a return avoidance pre-sales practice - here, in the form of a three-dimensional (3D) foot scanner with accommodating product recommendation software - can reduce fit uncertainty by providing fit verification to the customer. Studying the actual costs of product returns is important for retailers to understand how returns impact their financial performance. The cost reductions provide an impetus for retailers to adopt virtual fit verification technologies so as to avoid returns. We use a downstream retailer perspective and consider the product flow as beginning when the customer order is placed, followed by delivery, return, and reshelving in the warehouse.

\section{Theoretical background}

In our paper, we define the term fit uncertainty as the customer's experience of doubt as to whether a product physically fits. Experience products are products whose attributes are difficult to transfer from one party to another without the customer physically examining the product (Nelson, 1970); as such, fit verification tools are needed for these products. 
Fit uncertainty is a major cause of product return costs (Hong and Pavlou, 2014; Misra and Arivazhagan, 2017). The customer's pre-sales activity to mitigate fit uncertainty are reflected in the customer's shopping behavior.

We define pre-sales practices as activities in which customers engage on their path to reaching a purchase decision, and post-sales practices as practices that compensate fit uncertainty after the customer's purchase decision. Here, pre-sales practices mitigate fit uncertainty before returns occur, whereas post-sales practices deal with the consequences of bad fit. To position our paper in the literature, we review relevant studies assessing fit-related product return costs, along with research on avoidance practices. Avoidance practices aim to mitigate fit the pre-sales uncertainty experienced by customers and to reduce post-sales return costs. The extent to which pre-sales practices mitigate fit uncertainty impacts the costs arising from returns.

\subsection{Post-sales fit uncertainty mitigation practices}

Post-sales practices employed by retailers to cope with bad fit include money-back guarantees, return policies and customization. Money-back guarantees allow customers to try on the products at home, and if they are not satisfied with the fit, they can return it. However, used products often cannot be sold again, and money-back guarantees have been shown to increase return rates (Walsh and Möhring, 2017). Return policies impact the customer's shopping and return behavior (Gu and Tayi, 2015; Janakiraman et al., 2016). For example, lenient policies could encourage customers to overorder and return, wherein customers order multiple products in different variants (such as the same product model in different sizes) with the intention of returning the least-fitting variant(s) (Mollenkopf et al., 2007). Overordering creates additional costs, particularly through extra picks of items intended to be returned, additional transports to return the least-fitting product(s) and additional inventory costs when the products are in the customer's evaluation loop. To restrict customers from returning, retailers sometimes add customization elements to products (Gu and Tayi, 2015) so that customers can add their name to the product or choose colors. Such post-sales practice often mean that customers cannot return the product, despite it not fitting.

\subsection{Pre-sales fit uncertainty mitigation practices}

To facilitate the customer's pre-sales fitting process, there are practices that are more or less advanced in terms of fit accuracy and ability to verify fit (Gustafsson et al., 2019). A basic presales practice is for the customer to gather information about the product so that they can obtain a better understanding of the product and make a more informed order decision. Useful online information can be gathered from, e.g., online customer reviews and forums (Minnema et al., 2016). Providing precise information about products on retailers' webshops offsets returns (De Leeuw et al., 2016; Hjort et al., 2019); this is the most common pre-sales practice retailers use (Hjort et al., 2019). Another common pre-sales practice is providing size charts that customers can use to inform themselves on how a certain size will fit them. As for more advanced pre-sales practices, customers engage with the technology pre-sale, which will hopefully alleviate fit uncertainty concerns. Technologies aimed at reducing fit uncertainty involve size and style recommendations, fit visualization, and fit recommendations (Miell et al., 2018). Size and style recommendations are based on questions asked of the customer; fit visualization interfaces show tension maps for the customer to assess tightness; and fit recommendation interfaces let customers try on different sizes after having inputted certain measurements.

Lenient return policies promote physical fit verification, since customers can verify the fit of the product at home, but this important fit verification activity could also occur earlier
Retail supply chain costs of product returns 
IJPDLM 51,8

880 in the customer's process, even before they place the order, and as such, reduce the number of returns and, subsequently, costs. Advanced technologies provide authentic fit information, and research has pointed to the use of digital product fitting using 3D scanning to create a digital model of the customer and product for recommending fitting products (Gustafsson et al., 2019; Miell et al., 2018), potentially enabling virtual fit verification. Previous research has proposed virtual try-ons and interactive trial rooms for customers to assess the fit of a product (Liu et al., 2017; Misra and Arivazhagan, 2017); however, such applications rely on standard customer models (avatars), which only provides the customer with fit information, since without actual body scanning data, the visualization may not realistically represent the fit. Advanced digital product fitting applications provide virtual fit verification, as opposed to fit information and visualization practices (Gustafsson et al., 2019); what these have in common is that they rely on scans of customers to verify the fit.

From the above information, we see that pre-sales practices all aim to mitigate fit uncertainty, but they vary in their ability to verify the fit of a product. Basic practices, such as size charts, are unable to verify the fit of the product, even though they may provide useful fit information. More advanced pre-sales practices provide virtual fit verification, which is a step above fit information and visualization. Fit verification implies that customers are informed about the actual fit of a product, whereas fit information informs customers' perception of fit. For instance, a customer may gather fit information from multiple online customer reviews, and from that, they can imagine which size is the correct one.

\subsection{Product return costs}

A general returns management process includes receiving the customer's return request, processing the return, crediting the customer and analyzing and following up on the return data (Rogers et al., 2002). Return avoidance is the umbrella term for practices related to avoiding returns before they enter the reverse product flow and product handling. Effective pre-sales avoidance practices minimize the cost of reverse logistics (Hjort et al., 2019; Rogers et al., 2002). Product return costs, or costs that are specific to reverse logistics in supply chains, include freight, receiving, handling and storage (Lambert and Pohlen, 2001). These costs are typical for retail supply chains, but there is no uniform way to estimate them.

In this paper, 'freight' refers to transportation and includes transporting returns and outgoing transports for returned parcels. Receiving and handling costs are grouped together under the term 'product return costs,' involving the receipt and handling of returns. Order picking is an essential metric in e-commerce: in this paper, it refers to the picking costs of items that are returned. Storage costs have perhaps the least common ground when it comes to estimating, as the inventory interest rate is the most problematic element (Azzi et al., 2014). We have included tied-up capital and inventory holding costs in storage costs. Product handling costs, tied-up capital, inventory holding costs, transportation costs, and orderpicking costs are all relevant from a return perspective and are common metrics for retail supply chains. These costs are easy to comprehend from an industry perspective and can, with a little adaptation, be transferred to other contexts. Thus, we deem these costs as the most relevant to estimate.

Cost awareness among internet retailers is limited (Hjort et al., 2019). Ketzenberg et al. (2020) added the perspective of the profit losses of product returns, focusing on fraudulent or abusive customer return behavior. We see an opportunity in diving deeper into categories of product return costs to expand the knowledge of the components of profit loss. Our paper expands previous research by including cost elements incurred by product returns. 


\section{Research methods}

We use a mixed-method approach to investigate how fit uncertainty impacts product return costs in online retailing and how pre-sales fitting technology can reduce fit uncertainty.

\subsection{Case description, case selection and product selection}

This study uses a single case to understand the fit uncertainty phenomenon in depth (Voss et al.,2002). This allowed us to estimate product return costs in the e-commerce setting of the case. We deemed one case to be sufficient for our purpose of estimating product return costs, as detailed data were required, and we had good access to the case. We tested an existing digital product fitting technology as an intervention and verified its outcomes, making the methodology approach suitable for building and validating the cost model in Table A1 (Oliva, 2019). The results stem from a single case, leading to issues of generalizability to other contexts. However, the cost model and the case are clearly and thoroughly described (Ketokivi and Choi, 2014), and the user of the model can easily understand which parameters to change given a new context, making the model transferrable to other contexts.

The unit of analysis is product return costs and how the technology influences fit-related returns, and the unit of observation is the case company's e-commerce operations. The case company is a Scandinavian footwear retailer with several physical stores as well as e-commerce operations. The retailer sells its own premium footwear brand, with product prices in the range of $€ 90-€ 250$. A third-party logistics (3PL) provider manages the warehouse operations: its tasks include picking and packing customer orders, receiving and sorting incoming goods, receiving and sorting returned goods, and adjusting stock levels. A 3PL transportation provider collects packed customer orders daily at the warehouse and delivers them to pick-up points, physical stores, or the end-customer's home.

The case was suitable for this study because it has an established e-commerce business and no current fitting technology on its webshop. Studying this retailer yielded an understanding of how traditional e-commerce operates when customers have no external tools to aid them in product fitting.

\subsection{Research design and process}

Figure 1 summarizes the research design and research process. The first step was to conduct a case study to observe how fit uncertainty affects the retailer's current e-commerce operations.

In the second step, we tested how an existing digital product fitting technology can reduce fit uncertainty for the retailer's products. The retailer offers a wide variety of shoes, of which 16 products were selected for use of the fitting technology. The selected products were representative of the retailer's assortment and included pumps, ballerina flats, boots, sneakers, and shoes with heels. The test is not meant to be an actual solution but rather to demonstrate how customers choose products when given personal fit information and recommendations.

In the third step, based on our knowledge of the returns handling process, customers' return reasons, and potential levels of fit verification, we re-calculated fit-related product return costs.

\subsection{Data collection}

3.3.1 Data for mapping the returns handling process. Table 1 shows the interviews we conducted, and Table A2 presents the interview protocol. We also visited the warehouse and observed the product flow from point of receipt to reshelving.
Retail supply chain costs of product returns 
IJPDLM

51,8

882

Figure 1.

Research design and process
Purpose: to determine how fit uncertainty impacts product return costs in online retailing and how digital product fitting, a presales fitting practice, can reduce fit uncertainty

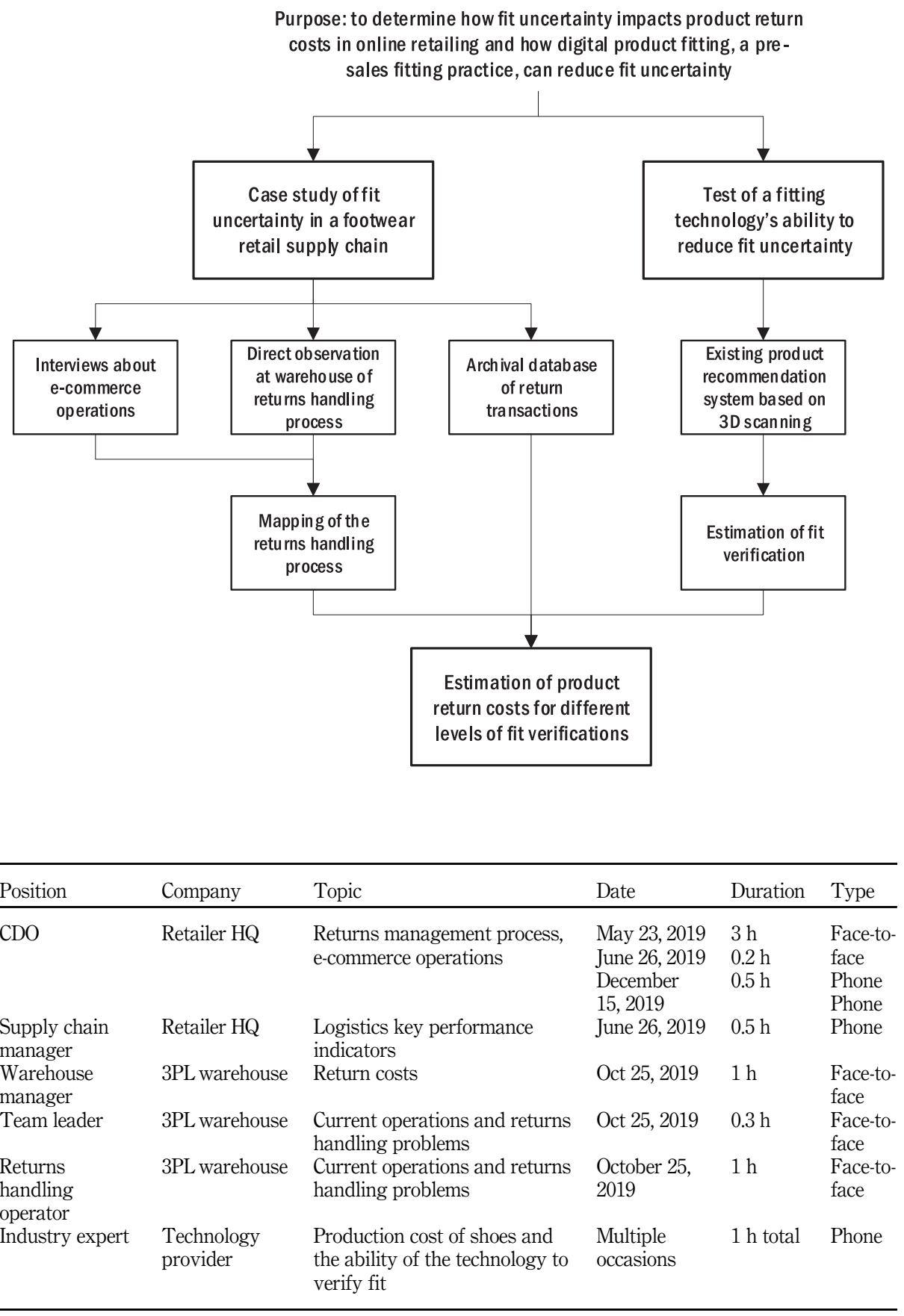

\begin{tabular}{|c|c|c|c|c|c|}
\hline Position & Company & Topic & Date & Duration & Type \\
\hline $\mathrm{CDO}$ & Retailer HQ & $\begin{array}{l}\text { Returns management process, } \\
\text { e-commerce operations }\end{array}$ & $\begin{array}{l}\text { May 23, } 2019 \\
\text { June 26, } 2019 \\
\text { December } \\
15,2019\end{array}$ & $\begin{array}{l}3 \mathrm{~h} \\
0.2 \mathrm{~h} \\
0.5 \mathrm{~h}\end{array}$ & $\begin{array}{l}\text { Face-to- } \\
\text { face } \\
\text { Phone } \\
\text { Phone }\end{array}$ \\
\hline $\begin{array}{l}\text { Supply chain } \\
\text { manager }\end{array}$ & Retailer HQ & $\begin{array}{l}\text { Logistics key performance } \\
\text { indicators }\end{array}$ & June 26, 2019 & $0.5 \mathrm{~h}$ & Phone \\
\hline $\begin{array}{l}\text { Warehouse } \\
\text { manager }\end{array}$ & 3PL warehouse & Return costs & Oct 25,2019 & $1 \mathrm{~h}$ & $\begin{array}{l}\text { Face-to- } \\
\text { face }\end{array}$ \\
\hline Team leader & 3PL warehouse & $\begin{array}{l}\text { Current operations and returns } \\
\text { handling problems }\end{array}$ & Oct 25, 2019 & $0.3 \mathrm{~h}$ & $\begin{array}{l}\text { Face-to- } \\
\text { face }\end{array}$ \\
\hline $\begin{array}{l}\text { Returns } \\
\text { handling } \\
\text { operator }\end{array}$ & 3PL warehouse & $\begin{array}{l}\text { Current operations and returns } \\
\text { handling problems }\end{array}$ & $\begin{array}{l}\text { October } 25 \\
2019\end{array}$ & $1 \mathrm{~h}$ & $\begin{array}{l}\text { Face-to- } \\
\text { face }\end{array}$ \\
\hline Industry expert & $\begin{array}{l}\text { Technology } \\
\text { provider }\end{array}$ & $\begin{array}{l}\text { Production cost of shoes and } \\
\text { the ability of the technology to } \\
\text { verify fit }\end{array}$ & $\begin{array}{l}\text { Multiple } \\
\text { occasions }\end{array}$ & $1 \mathrm{~h}$ total & Phone \\
\hline
\end{tabular}

Table 1.

List of interviews 
3.3.2 Data for estimating product return costs. Data for estimating product return costs were obtained from several sources. Interview data contributed some figures, such as the overall return rate for the retailer in 2018. In addition to interviews, we studied return transactions data taken from the warehouse's business system, which contains all returns to the retailer with the customers' stated reasons for returning the product. The return data established the number of returns, on which the calculations were based. For the four bestselling products, we studied both orders and returns logged with timestamps to analyze lead time, which was used in calculating tied-up capital and inventory holding costs. The bestsellers were also returned the most, making them an excellent subset for analyzing lead time from when the order was picked at the warehouse until the order was returned to the warehouse. To calculate the product return rate, when a digital product fitting technology was applied to the case retail supply chain, we performed a test that estimated virtual fit verification rates. The goal was not to test a practice that would reduce fit uncertainty in real life, but rather to test the technology and its potential for virtual fit verification.

3.3.3 Test of digital product fitting technology for virtual fit verification. The technology was set up in a physical store where the assortment was available for testing. The chief digital officer (CDO) carefully selected 17 participants who were in-house employees at the headquarters; four were men and 13 were women, which is representative of the retailer's customer base. Prior to the test, we sent three sizes for each of the 16 test products to the scanner provider, who scanned the products on the inside and stored the inside scans in a digital product database. Based on the three sizes sent, the software predicted the fit of the remaining sizes.

The scanner consists of a platform approximately $80 \times 80 \mathrm{~cm}$ in size, and a camera encircling the customer's feet on a magnetic loop. The scanner is accompanied by a portable tablet for presentation purposes. Upon scan completion, a 3D model of the customer's feet is produced, with several key measures. When the scanner has run the customer scan against the digital product database, the tablet presents a list of the best-fitting shoes in the database. A customer may have an idea of the type of shoes they want prior to shopping, but this paper focuses on the fit of the shoes and, therefore, fit is the most important quality considered. Advanced algorithms summarize the fit calculations, showing the degree of fit as two bars representing the left foot and the right foot for each pair of shoes. The bars are color-coded in green: the greener the bar, the better the fit. The fitting technology is among the most accurate fit verification tool available on the market. We tested how the participants responded to the recommendations. The participants had no information other than the virtual fit verification provided by the foot scanner, so no other influencing factors (e.g. shipping and return conditions) were present. The test progressed through five steps, and the CDO collected the responses from the participants in a data sheet, which we later analyzed.

(1) The participant stated their ordinary shoe size (to distinguish how the customer's "believed" size differed from the size recommended by the scanner).

(2) The CDO scanned the participant's feet, and foot data were derived from the customer scan.

(3) The CDO selected shoes recommended by the scanner for the participant to try out.

(4) The participant rated the shoes on a scale from one to five, where one represented "does not fit at all" and five represented "fits perfectly."

(5) The participant then tested alternative shoe sizes that they chose themselves and rated them on the same 1-5 scale.

3.4 Data analysis and reliability

3.4.1 Analyzing fit uncertainty in the footwear retail supply chain. From the interviews, we obtained insight into the costs that fit uncertainty has had on the retailer's e-commerce
Retail supply chain costs of product returns 
IJPDLM 51,8

884

operations and which practices the retailer has used to mitigate fit uncertainty. The interview data led to a description of the retailer's e-commerce business and a flow chart showing the return process, from the incoming customer order to the return being returned to the warehouse shelf. The flow chart was jointly produced with the $\mathrm{CDO}$ and was confirmed and complemented by our direct observations at the warehouse. In a final step, the warehouse manager validated the flow chart.

To understand the magnitude of product returns and why they occur, we studied return data on all 400 products in the retailer's assortment and analyzed the data in terms of the number of returns and the reasons for returning.

The returns operator at the warehouse explained and demonstrated the process of inputting received returns into the business system, thereby enabling correction of inconsistencies in the return data. In a few instances, customers had given multiple reasons for the returns; these combined responses included the true return reason, as well as either "other" or "unmet expectations." The two latter reasons were removed from the combinations, since they echoed the true reason for the return (e.g., a customer may report that the products were too small, thereby not meeting the customer's expectations).

3.4.2 Analyzing virtual fit verification. The test data resulted in several measures: estimations of customers' likelihood to keep or return products, the average number of shoes tested per customer, the most recommended shoes, and how the participants' stated size differed from the scanner-recommended size. The measure of relevance for the calculations is the likelihood of keeping or returning products, based on the test's fifth step. The participants were able to try on the shoes that the technology recommended as well as alternative sizes to verify the fit.

We view it as advantageous that the participants were in-house employees, since they likely knew which size they wore in the retailer's brand products and thus could give a more considered and accurate rating. In the fifth step, the participants tried on an alternative size of the recommended shoe that they believed would fit. It is possible that the employees knew more about the fit of the retailer's shoes and wore the shoes more frequently compared to conventional shoppers, which poses validity issues to our test. We are aware of this limitation and advise the reader to keep this in mind. The participants used the fit knowledge they obtained from the scanner's recommendation and, from that point of reference, opted to go up or down in size. A randomized sample of conventional shoppers would have used the same point of reference when deciding upon a different size, so it could be that tacit fit knowledge is not a bias here, but it very well could be. It is also possible that the in-house employees were biased, either toward wanting the research results to be positive or being overly critical.

3.4.3 Analyzing product return costs. We calculated key costs that we considered as impacting the supply chain the most, and that were in line with what previous research had pointed out as important measures (Lambert and Pohlen, 2001; Rogers et al., 2002). These included product handling costs, tied-up capital for "products in evaluation," inventory holding costs, transportation costs, and order-picking costs.

To estimate how fit uncertainty affects these costs, we calculated three situations: (1) all returns (not only fit-related) so that we could determine the total cost of returns, (2) costs associated with fit uncertainty and (3) return costs when applying different virtual fit verification return rates. The first two situations were based on return data for all of the retailer's products, along with the order and return data for the four bestselling products. The third situation was based on Situation 2 but with three applied return reduction rates that represented the impact of digital product fitting technology. The fitting technology's difficulty in calibrating itself to these types of fashion shoes led us to use three different rates. The industry expert indicated that an $80 \%$ verification rate is possible. Instead of contributing the fitting technology's ability to reduce returns, we calculated its allowed costs for breaking even by the first year of operation given the three verification rates. We used 40 
and $60 \%$ as the two lower rates, to show that it is worth investing in virtual fit verification technology, despite the fact that it does not function flawlessly every time. Calculating the fitting technology's allowed costs improved the cost model's generalizability, as the focus shifted from this particular technology to any type of fitting technology.

Table A1 shows the model used for return costs. Equation (1) indicates the total cost. Equation (2) details the product handling costs. The warehouse manager provided the hourly rate that the retailer pays the warehouse for handling incoming returns, based on the number of returns handled per hour. The receiving cost of the returns is also part of the product handling costs; this includes unloading the truck, splitting parcels, and transporting the returns to the designated handling area. We assumed that the receiving cost per unit was half of the product handling cost on average, since receiving excludes the quality check and manual registration of the return into the business system.

Equation (3) indicates the tied-up capital. We calculated two figures: one is based on the average commercial price of the products, and the other is based on the retailer's purchase price. Both figures are of note, since they depict the actual tied-up capital the retailer faces by having "products in evaluation," along with the tied-up capital that cannot be sold but is meant to cover the retailer's costs and add to its profit margin. The CDO provided us with the average purchase price of a product $(€ 150)$, and the technology provider informed us that, in general, the purchase price is one-fifth of the commercial price (in this case, $€ 30$ ).

Equation (4) indicates the inventory holding costs caused by returns. We assumed an inventory holding interest rate of $25 \%$, a commonly used interest rate (Azzi et al., 2014), and based the calculation on the average purchase price of the product. However, since the interest rate is unknown and may vary, we also conducted a sensitivity analysis.

Equation (5) gives the transportation costs caused by returns. We made assumptions about the distribution of ordered products per parcel. Since the retailer offers free shipping, and the 3PL transportation provider does not charge for collecting parcels at pick-up points, the cost of returning depends on the transportation cost to the end-customers. According to the business system, the CDO shared that two-thirds of orders placed during 2018 were single-item orders. The average return rate for the same year was $28 \%$. These two figures provided sufficient information to determine approximately how single-item orders were distributed. The remaining $33 \%$ were then distributed according to five different systems, $\delta_{n}\left(q_{k}\right)$, accounted for in Table A1. As for the first assumed distribution, $\delta_{1}\left(q_{k}\right)$, multi-orders from customers (orders exceeding one item) were evenly distributed, revealing the same likelihood for customers who order two items or up to 11 items. As for the other four distributions, $\delta_{2-5}\left(q_{k}\right)$, we assumed exponential decline, since it is more likely that customers order two items than 11 items. The transportation cost to the end-customers, $c_{\operatorname{tra}}\left(q_{k}\right)$, depends on the weight of the dispatched parcel. Several shoe types were weighed to determine the average weight of a pair of shoes, and we determined an average weight of one kilogram.

Equation (6) provides the order-picking costs caused by returns. The warehouse manager provided the picking cost per order, per order line, and per item. We reasoned that it was unlikely that there would be more than one item per order line, and we added the picking cost per order line to the picking cost per item. The order-picking costs for returns depend on the number of items in the order; therefore, we assumed the same order distribution as that of the transportation costs.

\section{The footwear retail supply chain}

Here, we present the retailer's typical customers and their order and return patterns. The data in this section were obtained from three sources: data derived from interviews with the CDO and the warehouse manager, ${ }^{[i]}$ warehouse transaction data; ${ }^{[i]}$ and data from the retailer's business system. ${ }^{[i i i]}$ The superscripts indicate the data source.
Retail supply chain costs of product returns 
IJPDLM 51,8

886

\subsection{The typical customer and order patterns}

The retailer's typical e-commerce customer is a 25-40-year-old woman who purchases shoes once or twice a year and lives in an urban area. ${ }^{[i]}$ The customer base is approximately $70 \%$ female and $30 \%$ male. ${ }^{[i]}$ The typical customer has a discount-driven shopping behavior, with club days and Black Friday spike e-commerce orders. The average purchase amounts to $€ 150 .{ }^{[i]}$ Previously, the typical customer ordered shoes in only one size, but the retailer has observed that overordering is increasing (i.e., ordering shoes in several sizes with the intent to return the worst-fitting). ${ }^{[\mathrm{i}]}$ As of 2018, roughly two-thirds of all orders were single-size orders. ${ }^{[i]}$ Customers choose pick-up point delivery and almost never choose in-store pickup.

Non-club members have 30 days to return non-discounted items, while club members have 60 days. For discounted items, the customer has 14 days to return the item, counting from the delivery day. On average, returned shoes are back at the warehouse within 15 days. ${ }^{[i]}$

\subsection{Return patterns}

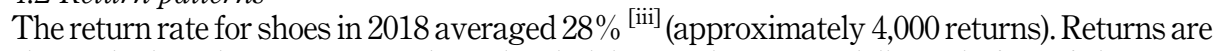
charged when they are returned at a local pick-up point. Home delivery is free of charge on orders exceeding $€ 99$. Shipping is always free at pick-up points and stores. Most customers use pickup points for returns.

On average, customers return 1.3 products per parcel. The top diagram in Figure 2 shows the distribution of returns per parcel. The warehouse receives approximately 2,400 parcels each year, with a total of 3,100 returned items. The returns dataset had 1,761 unique customer IDs and 324 duplicate (or more) customer IDs, for a total of 2,229 returned products; this indicates that $18 \%$ of the returns were "multi" returns (returns where customers returned more than one product). Since the customer ordering behavior is unknown for this dataset, $15 \%$ (1-0.67 [single-item orders] - 0.18 [known multi-orders]) of multi-orders are hidden, where customers ordered multiple products but decided to return only one.

Studying the customers' reasons in the returns dataset revealed that the most frequent reason of return is a poor fit (products being too small or too large), accounting for $55 \%$ of the returns, as seen in the bottom diagram in Figure 2. We analyzed whether some types of shoes (open shoes, such as pumps and ballerina flats; closed shoes, such as boots and sneakers; and shoes with heels) were more prone to be returned due to fitting issues, but the returns were evenly distributed across shoe types.

In separate analyses of the return reasons for the retailer's brand and for its additional brands, the results echoed the overall return reason, namely, poor fit. An interesting difference between the return reasons for the retailer's brand and for its additional brands is that customers who shop the retailer's brand are more prone to return due to the products not meeting their pre-purchase expectations (33\% compared to $21 \%$ ), while customers who shop the other brands are more prone to return due to fitting issues. An explanation of this difference in return reasons could be that the retailer's own brand products are available in full sizes only. The other brands can exist in half and quarter sizes as well, making the size scale more difficult to choose from. Repurchasing and brand-loyal customers likely know which size they typically order, and thus have a better idea as to which size to order.

Figure 3 shows the retailer's return handling process, from the time a customer places an order until the time the returned item(s) are back in stock and resalable. As seen in Figure 3, the returns handling activities make up one-third of the activities that orders involve. The calculations presented later in the paper show the costs of these activities.

\section{Test results of the digital product fitting technology}

We tested how well the digital product fitting technology can provide virtual fit verification to reduce e-commerce return rates for fashion shoes. 


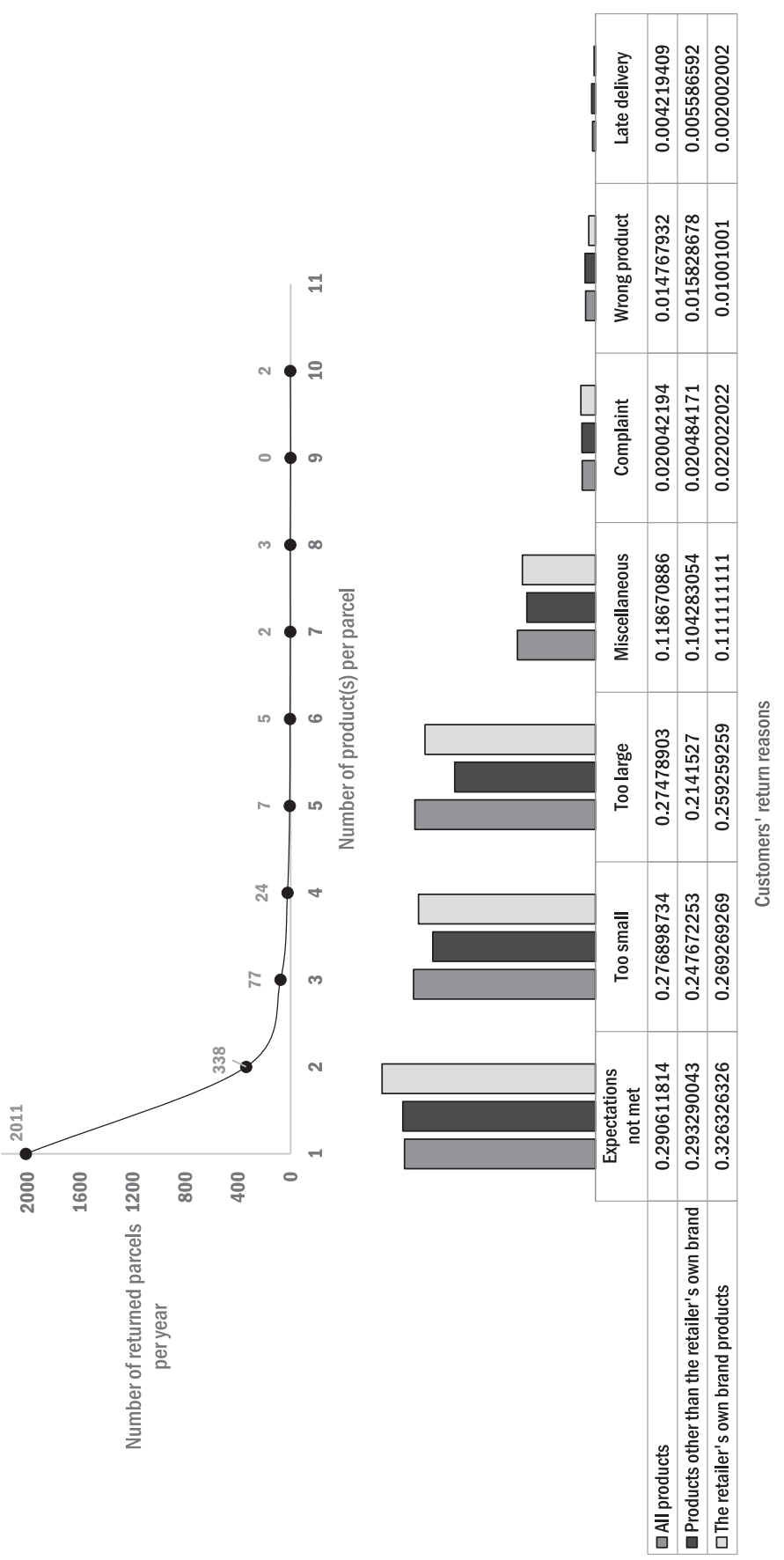

Retail supply chain costs of product returns

887

Figure 2.

The top diagram shows the distribution of items in returned parcels. The bottom diagram shows customers' return reasons 


\section{IJPDLM 51,8}

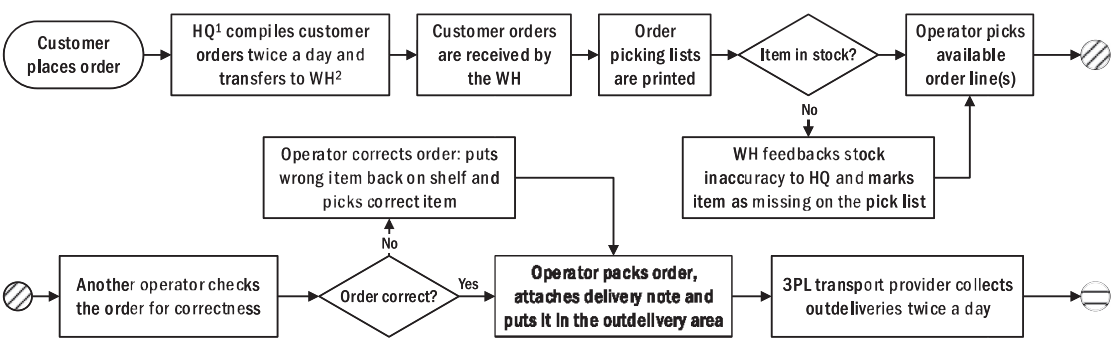

888

Figure 3.

The retailer's returns handling process, from the time a customer places an order until the time the returned item(s) are back in stock and resalable
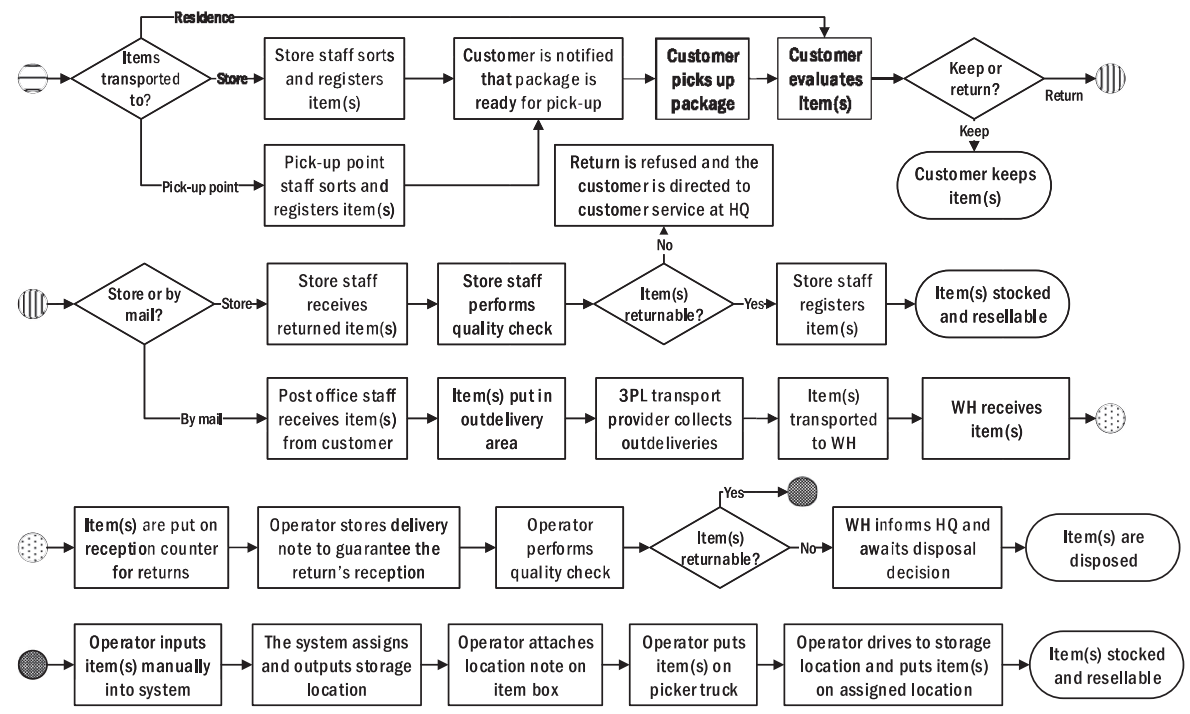

In total, 38 pairs of shoes were physically tested by the participants, with an average of 2.2 pairs tested per test customer. The participants deemed that the recommended shoes fit and indicated that they would have kept the shoes in ten out of 38 cases, approximately $25 \%$ of the time. If the scanner would have been better calibrated for these types of fashion shoes and had given recommendations based on the participants' alternative tests (the test's fifth step), the customers reported that they would have kept the shoes in 16 out of 19 cases, or approximately $80 \%$. On average, the system recommended half a size larger than the participants' personally stated size. When the participants tried alternative sizes that they chose themselves, they opted for a smaller size compared to the scanner's recommendation in 15 out of 19 cases.

The current calibration of the system did not provide virtual fit verification for all recommendations, since the technology struggled to calibrate to the type of products studied. With the current outcome of verifying fit for $25 \%$ of recommendations, the fitting technology could be used as decision support, and in that capacity, only reduce the number of returns to a limited degree. As expected, the most accurately recommended product was a sneaker, since that type of shoe is most similar to closed footwear, for which the technology was developed. One of the bestselling pumps - which has the highest return rate-had no matches, indicating the technology's difficulty in calibrating to an open shoe with heels. It seems that the tested technology was unsuitable for this type of fashion footwear, and that it requires further development in order to calibrate the fitting. 
Even though the technology may not be able to verify fit, its use after improved calibration can still prevent potential buys where the customer considers a certain product and is unaware of a bad fit. It may also help a customer to choose correctly between two sizes. This technology is useful for decision support, in that it displays fit as two bars in conjunction with a list of recommended products. For example, the technology may display two half-filled bars, so the customer knows that the fit is not perfect. At that point, it is up to the customer to decide whether they will be satisfied with the fit.
Retail supply chain costs of product returns

\section{Modeling product return costs}

This section presents the results of using the developed model for fit-related return costs in three situations (Table 2). The figures are presented in EUR/year as an absolute cost. The calculated costs include product handling costs, tied-up capital, inventory holding costs, transportation costs, and order-picking costs. Product handling indicates the costs of receiving returns when they arrive at the warehouse and their subsequent quality inspection and restocking. Tied-up capital is the cost of ordered products being in the customer's evaluation loop and is based on the lead time from when the product is dispatched from the warehouse until it is re-received by the warehouse. Inventory holding costs are the tied-up capital costs multiplied by the inventory interest rate. Transportation costs are the costs of sending an order associated with returns to the customer and the subsequent costs of the return transportation. Order-picking costs are determined by the number of delivered items and are an estimate of the costs of picking items that are returned.

For the figures in Table 2 to make sense, they need to be viewed in relation to the net sales of shoes each year. Since the overall return rate is $28 \%$ and the transaction data contain 2,229 returns over a 261 -day period, the net sales of shoes is $\frac{2229 \times 365}{261 \times 0.28}=11,133$ pair of shoes. The return cost per the net sales of shoes is then $52,501 / 11,133 \approx 5$ EUR per shoe, which is approximately $17 \%$ of the shoes' prime cost (which is assumed to be $€ 30$ ).

The savings per pair of shoes (Situation 3, reduction rate $80 \%$ ) is $(29,263-5,843)$ / $11,133 \approx 2.1 \mathrm{EUR}$, which is $2.1 / 30 \approx 7 \%$ of the prime cost of a pair of shoes. The savings per pair of shoes then ranges between $€ 1.1$ and $€ 2.1$, depending on the reduction rate. The savings per pair of shoes sold may appear low, given that the retailer is not a major actor on the market, and that the sales also stem from physical stores. However, when such savings are extrapolated to larger online retailers, the cost of a few euros per sold pair of shoes is

\begin{tabular}{|c|c|c|c|c|c|}
\hline \multirow[b]{2}{*}{ Costs [EUR per year] } & \multirow{2}{*}{$\begin{array}{l}\text { Situation } 1 \\
\text { all returns }\end{array}$} & \multirow{2}{*}{$\begin{array}{c}\text { Situation } 2 \\
\text { fit-related } \\
\text { returns }\end{array}$} & \multicolumn{3}{|c|}{ Situation $3^{*}$} \\
\hline & & & $\begin{array}{l}40 \text { percent } \\
\text { verification }\end{array}$ & $\begin{array}{l}60 \text { percent } \\
\text { verification }\end{array}$ & $\begin{array}{l}80 \text { percent } \\
\text { verification }\end{array}$ \\
\hline Product handling costs & 21,047 & 11,576 & 6,945 & 4,630 & 2,315 \\
\hline Returns operator & 14,031 & 7,717 & 4,630 & 3,087 & 1,543 \\
\hline Receipt operator & 7,016 & 3,859 & 2,315 & 1,543 & 772 \\
\hline Tied-up capital & - & - & - & - & - \\
\hline based on purchase price & 3,844 & 2,114 & 1,269 & 846 & 423 \\
\hline based on commercial price & 19,221 & 10,571 & 6,343 & 4,229 & 2,114 \\
\hline Inventory holding costs** & 4,805 & 2,643 & 1,586 & 1,057 & 529 \\
\hline Transportation costs & 16,943 & 9,684 & 5,603 & 3,743 & 1,883 \\
\hline Order picking costs & 5,863 & 3,246 & 1,967 & 1,330 & 693 \\
\hline $\begin{array}{l}\text { Total costs (tied-up capital is } \\
\text { based on purchase price) }\end{array}$ & 52,501 & 29,263 & 17,370 & 11,606 & 5,843 \\
\hline Allowed fitting technology costs & - & - & 11,705 & 17,558 & 23,410 \\
\hline
\end{tabular}

Table 2.

Return costs per year 
IJPDLM 51,8 considerable when operating with low margins and high volumes. As such, if retailers debate implementing digital product fitting technology in their webshops, the cost of the fitting technology (including both purchase cost and all operating costs) may not exceed $€ 1.1$ per pair of shoes if the verification rate is $40 \%, € 1.6$ if the verification rate is $60 \%$ and $€ 2.1$ if the verification rate is $80 \%$. On a yearly basis, that allows a fitting technology cost of around $€ 12,000$ if the technology can reduce fit-related returns by $40 \%$ reduction, around $€ 18,000$ if the technology can reduce fit-related returns by $60 \%$ reduction and around $€ 23,000$ if the technology can reduce fit-related returns by $80 \%$.

\section{Discussion}

Researchers have studied product returns widely, but little empirical analysis has been conducted on the drivers of costs of product returns and how these costs may be affected. This paper adds to the understanding of the reasons for product return costs in the retail supply chain literature, elaborating how fit uncertainty impacts product return costs and how digital product fitting technology can reduce fit uncertainty as a pre-sales return avoidance practice.

The contribution is based on an analysis of the return process and the costs of an internet retailer. Our results support previous findings (Hong and Pavlou, 2014; Misra and Arivazhagan, 2017) that product fit uncertainty is a major cause of product returns. We contribute with a method to identify fit uncertainty-related costs in retail supply chain operations. To our knowledge, very few previous studies have examined actual costs of product returns. Ketzenberg et al. (2020) modeled the effects of abusive product returns, and while fit uncertainty might give rise to abusive returns (as in the case of ordering multiple sizes of a pair of shoes), such behavior can be deemed legitimate given the presence of fit uncertainty. To address fit uncertainty, one typical post-sales practice is to employ strict return policies (Hjort et al., 2019; Janakiraman et al., 2016). Strict return policies make the returning process a hassle for the shopper to prevent returns and are not helpful for shoppers ordering fit-dependent products, since they might need to verify the fit of the product before purchase. By contrast, lenient return policies promote the customers' fitting process by providing free shipping and returns but may also lead to increased product returns and, hence, greater product return costs.

Instead of addressing return policies, this paper has looked at a pre-sales return avoidance practice that aims to facilitate the customer in their decision-making around which size to order-and in so doing to avoid returns. Current technologies aimed at reducing fit uncertainty and thus avoiding returns include size and style recommendations, fit visualization and fit recommendations (Miell et al., 2018), but these are inaccurate when it comes to fit verification. Our tested digital product fitting technology provides virtual fit verification, which is a step up from just providing size information, as the technology provides the actual fit of the product instead of just making the customer process information and come up with an idea of how the product would fit. This type of pre-sales practice reduces the importance of post-sales practices and return costs, especially costs pertaining to customer order and return behavior.

The results of this study show that a non-negligible $55 \%$ of returns are subject to poor fit. We concur with Hong and Pavlou (2014), who linked the origin of product returns due to fit uncertainty with inadequate conveyance of fit information on retailers' websites. Hjort et al. (2019, p. 777) stated: "[ . . . ] retailers with a relatively high return rate work almost exclusively to inform customers (mostly about products) before purchase to avoid returns." However, while this information practice may prevent some fit-related returns, it does not address all of them, and we see the need to research additional ways of improving fit information on retailers' websites, especially in terms of virtual fit verification. A benefit of our tested fitting 
technology is that it provides fit verification based on the customer's own feet in a clear and comprehensible way.

We tested this existing fitting technology to understand how it impacts product fit uncertainty as experienced by end-customers. The test was carried out to estimate how the participants perceived the accuracy of the fitting technology to determine if they would keep the shoes recommended by the technology. However, the results were disappointing, due to the technology's difficulty in calibrating to this type of fashion footwear (i.e., open shoes, such as pumps and ballerina flats, and shoes with heels), which seem to be difficult shapes to measure and scan. If the technology were better calibrated to fashion shoes, we believe it would function better in providing virtual fit verification. The scanner's calibration issues and the small set of possibly biased participants prevent us from accurately estimating the extent to which the fitting technology can reduce fit-related returns. For the fitting technology to be worth investing in (i.e., to break even by the first year in operation), it may cost $€ 12$ $€ 23,000$, including any personnel costs for implementing the fitting technology on a webshop. (The better and more accurate the technology is, the more it may cost.)

Our findings show how fit-related product returns give rise to higher product handling costs, increased tied-up capital, increased inventory holding costs, increased transportation costs and higher order-picking costs in retail supply chains. The return cost per net sales of shoes in the case company was $17 \%$ of the prime cost of a pair of shoes. By providing virtual fit verification, the case retailer could reduce the cost of the returns per net sales of shoes by 4 $7 \%$ (depending on the fit verification rate). The potential savings figure is relatively low due to many other return reasons: $45 \%$ of the returns were sent back for other reasons, such as the products not meeting the end-customers' expectations.

One disadvantage of the technology is that its applicability in e-commerce is limited, as it requires the customers to physically visit a scanner location. One possible implementation would be an app with scanning functionality connected to the customer profile, enabling the customer to scan their foot at home and use the fit of the scan for online shopping. An alternative, omnichannel implementation of this type of technology, would be to allow the customers to visit a physical store to use the technology and then order online. In this way, both channels would be useful in retail supply chains: the physical store for engaging with the end-customer, and the e-commerce channel for offering a wider assortment to end-customers. However, the technology would only be available to customers in the store location area.

Furthermore, a dilemma around how customers shop regarding fit is that the shoe type is often easier to fit. Both combinations of "good fit/wrong type" and "poor fit/right type" would likely result in returns, as some shoes are just not meant for some feet. Therefore, virtual fit verification is needed for customers who order shoes online to prevent guaranteed "no sales" orders, especially for the combination of "poor fit/right type." Therefore, we believe the fit verification properties of this fitting technology are worth striving for.

\section{Conclusions}

The paper reveals how fit uncertainty impacts product return costs in online retailing and how pre-sales digital product fitting technology can reduce fit uncertainty. Theoretically, our paper contributes to understanding how customers interact with and use pre-sales product fitting technology for virtual fit verification to reduce fit uncertainty. We contribute to the line of research dealing with avoidance practices to offset returns in online retailing, identifying the important role of the pre-sales fitting activity of virtual fit verification, whereas previous research has focused on conveying fit information (De Leeuw et al., 2016; Hjort et al., 2019; Miell et al., 2018).

Managerially, the paper shows how return activities drive costs, and retailers can use the model to follow up on changes in return behaviors and subsequent return costs. While this 
IJPDLM 51,8

892

model was made for the fashion shoes setting, it could be applied in other settings, such as a planning model to determine return costs. In such an application, the number of returns must be obtained from a case, along values for other parameters, including inventory holding rate, number of returns, etc. These costs, when adapted to the user, are general for most retailers, in terms the return activities executed and the presence of quality checking activities of returns. The calculated potential savings and return rates used in the model should be taken cautiously, since the digital product fitting technology was only tested by a limited number of possibly biased employee participants.

A limitation of our study is that it is solely based on return data. Future studies should consider studying customer order data in conjunction with return data to determine actual customer ordering behavior in the face of fit uncertainty. Customer ordering behavior is a large piece of the puzzle to understanding how customers act when facing fit uncertainty. Retailers could incentivize customers to make reliable orders with better pre-sales practices. If customers would be willing to invest more effort in the pre-sales stage, such as by engaging with product fit information, less effort would be needed in the post-sales stage.

Since few empirical studies show the effects of virtual fit verification, future studies should consider examining returns and order data where such tools have been applied, to make it possible to distinguish how the customers have used the tool. We also recommend conducting experiments to better understand how these tools help customers address fit uncertainty and decide on fitting sizes, as well as how this affects the number of returns. Other relevant areas for future studies concern extending the cost model, such as to incorporate sustainability costs - i.e., the costs of emissions associated with returns - or to incorporate lost sales i.e., products being delivered to customers and later being returned. For such calculations, both order and return transactions that are logged with customer IDs are needed.

\section{References}

Azzi, A., Battini, D., Faccio, M., Persona, A. and Sgarbossa, F. (2014), "Inventory holding costs measurement: a multi-case study", The International Journal of Logistics Management, Vol. 25 No. 1, pp. 109-132.

De Leeuw, S., Minguela-Rata, B., Sabet, E., Boter, J. and Sigurðardóttir, R. (2016), "Trade-offs in managing commercial consumer returns for online apparel retail", International Journal of Operations and Production Management, Vol. 36 No. 6, pp. 710-731.

Gu, Z. and Tayi, G.K. (2015), "Consumer mending and online retailer fit-uncertainty mitigating strategies", Quantitative Marketing and Economics, Vol. 13 No. 3, pp. 251-282.

Gustafsson, E., Jonsson, P. and Holmström, J. (2019), "Digital product fitting in retail supply chains: maturity levels and potential outcomes", Supply Chain Management: An International Journal, Vol. 24 No. 5, pp. 574-589.

Hjort, K., Hellström, D., Karlsson, S. and Oghazi, P. (2019), "Typology of practices for managing consumer returns in internet retailing", International Journal of Physical Distribution and Logistics Management, Vol. 49 No. 7, pp. 767-790.

Hong, Y. (Kevin) and Pavlou, P.A. (2014), "Product fit uncertainty in online markets: nature, effects, and antecedents", Information Systems Research, Vol. 25 No. 2, pp. 328-344.

Janakiraman, N., Syrdal, H.A. and Freling, R. (2016), "The effect of return policy leniency on consumer purchase and return decisions: a meta-analytic review", Journal of Retailing, Vol. 92 No. 2, pp. 226-235.

Ketokivi, M. and Choi, T. (2014), "Renaissance of case research as a scientific method", Journal of Operations Management, Vol. 32 No. 5, pp. 232-240.

Ketzenberg, M.E., Abbey, J.D., Heim, G.R. and Kumar, S. (2020), “Assessing customer return behaviors through data analytics", Journal of Operations Management, Vol. 66 No. 6, pp. 622-645. 
Lambert, D.M. and Pohlen, T.L. (2001), "Supply chain metrics", The International Journal of Logistics Management, Vol. 12 No. 1, pp. 1-19.

Liu, K., Zeng, X., Bruniaux, P., Wang, J., Kamalha, E. and Tao, X. (2017), "Fit evaluation of virtual garment try-on by learning from digital pressure data", Knowledge-Based Systems, Vol. 133, pp. 174-182.

Miell, S., Gill, S. and Vazquez, D. (2018), "Enabling the digital fashion consumer through fit and sizing technology", Journal of Global Fashion Marketing, Vol. 9 No. 1, pp. 9-23.

Minnema, A., Bijmolt, T.H.A., Gensler, S. and Wiesel, T. (2016), "To keep or not to keep: effects of online customer reviews on product returns", Journal of Retailing, Vol. 92 No. 3, pp. 253-267.

Misra, S. and Arivazhagan, D. (2017), "Interactive trial room -A solution to reduce the problem of rampant return of sold merchandise in fashion E-commerce business", Indian Journal of Science and Technology, Vol. 10 No. 16, pp. 1-4.

Mollenkopf, D.A., Rabinovich, E., Laseter, T.M. and Boyer, K.K. (2007), "Managing internet product returns: a focus on effective service operations", Decision Sciences, Vol. 38 No. 2, pp. 215-250.

Nelson, P. (1970), "Information and consumer behavior", Journal of Political Economy, Vol. 78 No. 2, pp. 311-329.

Oliva, R. (2019), "Intervention as a research strategy", Journal of Operations Management, Vol. 65 No. 7 , pp. $710-724$.

Rogers, D.S., Lambert, D.M., Croxton, K.L. and García-Dastugue, S.J. (2002), "The returns management process", The International Journal of Logistics Management, Vol. 13 No. 2, pp. 1-18.

Voss, C., Tsikriktsis, N. and Frohlich, M. (2002), "Case research in operations management", International Journal of Operations and Production Management, Vol. 22 No. 2, pp. 195-219.

Walsh, G. and Möhring, M. (2017), "Effectiveness of product return-prevention instruments: empirical evidence", Electronic Markets, Vol. 27 No. 4, pp. 341-350.

Weathers, D., Sharma, S. and Wood, S.L. (2007), "Effects of online communication practices on consumer perceptions of performance uncertainty for search and experience goods", Journal of Retailing, Vol. 83 No. 4, pp. 393-401.
Retail supply chain costs of product returns 


\section{IJPDLM}

IJPD
51,8

894

\section{No}

$C_{\text {ret }}$

$\delta_{n}\left(q_{k}\right)$
$C_{\text {hand }}$

$\delta_{n}\left(q_{k}\right)$
$C_{\text {hand }}$

$C_{\text {tied }}$

$C_{\text {inv }}$

$C_{\text {tra }}$

$C_{\text {pick }}$

$n_{r}$

$n_{\text {del }}$

$c_{\text {rec }}$

$c_{\text {res }}$

$q_{k}$

$\mu_{s}$

$r$

$r_{1}$

$r_{2}$

\section{Appendix}

Equation/

value

Equation (1)

product handling costs, $C_{\mathrm{h}}$. The yearly total cost of returns, $C_{\text {ret }}$, is the sum inventory holding costs, $C_{\text {inv }}$, and transportation costs, $C_{\text {tra }}$, and depends on the distribution of delivered products, $\delta_{n}\left(q_{k}\right)$ :

$C_{\text {ret }}=C_{\text {hand }}+C_{\text {tied }}+C_{\text {inv }}+C_{\text {tra }}+C_{\text {pick }}$

$n$th distribution where $n \in \mathbb{N}: n \in[1,5]$ ( $n$ is an integer between 1 and 5)

Total yearly product handling cost of returns. The product handling cost of

returns is the sum of receiving the returns when they arrive at the warehouse, $c_{\mathrm{rec}}$, and the subsequent quality inspection and restocking, $c_{\text {res }}$ :

$C_{\text {hand }}=n_{\text {del }} r\left(c_{\text {rec }}+c_{\text {res }}\right)$

tied $\quad$ Total yearly tied-up capital cost for returns. The tied-up capital depends on the number of returns that are in the customers' evaluation loops, $n_{r}$, the lead time for which the items are in the loops, $t$, and the retailer's purchase price of the item $p$ : $C_{\text {tied }}=n_{\text {del }} r t p / 365$

Total yearly inventory holding cost for returns when they are in customers' evaluation loops. The inventory holding cost is the tied-up capital multiplied by the interest rates:

$C_{\text {inv }}=C_{\text {tied }} \cdot(1+h)$

Total yearly transportation cost for returns. The transportation cost of returns depends on the distribution of delivered products, $\delta_{n}\left(q_{k}\right)$ and the fraction of items in order of how they are returned. Here, we calculated two cases. Case 1 concerns is where the customer decides to keep one of the ordered items and return the rest, and Case 2 is the worst-case scenario where the customer returns all ordered items. The transportation cost further depends on the weight of the parcel (the packed order), $c_{\text {tra }}\left(q_{k}\right)$. Seeing how the two cases did not affect the calculation to any greater extent, the calculations are solely based on the first and most realistic case $C_{\text {tra }}= \begin{cases}\sum_{k=1}^{11} \frac{r \delta_{n}\left(q_{k}\right)}{k} \cdot\left(c_{\text {tra }}\left(q_{k}\right)-c_{\text {cus }}\right), & \mid \text { Case 1: keep one item } \\ \sum_{k=1}^{11} r \delta_{n}\left(q_{k}\right) \cdot\left(c_{\text {tra }}\left(q_{k}\right)-c_{\text {cus }}\right) & \mid \text { Case 2: return all }\end{cases}$

Total yearly order-picking cost of the returns. The order-picking cost of returns depends on the number of delivered products, $n_{d e l}$, and how the delivered products are distributed, i.e. how many orders that contain $q_{k}$ items

$C_{\text {pick }}=\sum_{k=1}^{11} \frac{n_{\text {del }}\left(1-\mu_{s}\right)}{q_{k}} \cdot q_{k-1} \cdot\left(\frac{c_{\text {pick }}^{\text {order }}}{q_{k}}+c_{\text {pick }}^{\text {item }}\right)$

Total number of returns received by the warehouse each year

Total number of delivered/ordered products each year,

$n_{\text {del }}=\sum_{k=1}^{11} \delta_{n}\left(q_{k}\right)$

Equation (6)

Receiving handling fee per item for incoming returns [EUR]

Handling fee per item for quality inspecting and restocking the returns [EUR]

Quantity of items in an order, where $q_{k} \in \mathbb{N}: q_{k} \in[1,11]\left(q_{k}\right.$ is an integer between 1 and 11)

Fraction of single-item $\left(q_{k}=1\right)$ customer orders

$[1,11]$

0.67

Return rate, assumes any of the values of $r_{1}, r_{2}$, or $r_{3}$

$-$

0.28

Overall return rate used in Situation 1

Return rate for fit-related returns used in Situation 2. $r_{2}=0.55 r_{1}$
0.15

(continued)

Table A1.

The return costs model 


\begin{tabular}{|c|c|c|c|}
\hline Notation & Description & $\begin{array}{l}\text { Equation/ } \\
\text { value }\end{array}$ & $\begin{array}{l}\text { Retail supply } \\
\text { chain costs of }\end{array}$ \\
\hline $\begin{array}{l}r_{3} \\
c_{\text {pider }}^{\text {orde }}\end{array}$ & $\begin{array}{l}\text { Return rate derived from pilot test used in Situation } 3 . r_{3}=(1-0.8) r_{2} \\
\text { Cost per order [EUR] }\end{array}$ & $\begin{array}{l}0.03 \\
1.4\end{array}$ & returns \\
\hline $\begin{array}{c}\text { peck } \\
\text { ipem } \\
\text { ipick }\end{array}$ & Cost per item [EUR] (includes cost per order line, $€ 0.56$ ) & 0.94 & \\
\hline$p$ & The retailer's average purchase price of an item [EUR] & 30 & 895 \\
\hline$t$ & $\begin{array}{l}\text { Lead time for which the items are in customers' evaluation loops, i.e. the time } \\
\text { between the order having left the warehouse until it is back at the warehouse } \\
\text { [days] }\end{array}$ & 15 & \\
\hline$h$ & Inventory holding interest rate & 0.25 & \\
\hline$c_{\text {tra }}\left(q_{k}\right)$ & $\begin{array}{l}\text { Transportation fee to pick-up points for parcels containing } q_{k} \text { items [EUR] } \\
c_{\text {tra }}\left(q_{k}\right)=\left\{\begin{array}{cc}12.3, & \mid 1 \leq q_{k} \leq 2 \\
14.2, & \mid 3 \leq q_{k} \leq 4 \\
16.2, & \mid 5 \leq q_{k} \leq 6 \\
18.7, & \mid 7 \leq q_{k} \leq 8 \\
21.6, & \mid 9 \leq q_{k} \leq 10\end{array}\right.\end{array}$ & - & \\
\hline$c_{\text {cus }}$ & Customer's cost to return, paid to the retailer [EUR] & 4.9 & \\
\hline$\delta_{n}\left(q_{k}\right)$ & $n$th distribution where $n \in \mathbb{N}: n \in[1,5]$ ( $n$ is an integer between 1 and 5$)$ & - & \\
\hline$\delta_{1}\left(q_{k}\right)$ & $\begin{array}{l}\text { Customer order distribution based on } \mu_{s} \text { for single-item orders }\left(q_{k}=1\right) \text {, and } 1-\mu_{s} \\
\text { for multi-orders evenly distributed on orders for } 1<q_{k} \leq 10\end{array}$ & - & \\
\hline & $\delta_{1}\left(q_{k}\right)=\left\{\begin{array}{l}n_{\mathrm{del}} \mu_{s}, \quad \mid q_{k}=1 \\
n_{\mathrm{del}}\left(1-\mu_{s}\right) / 10, \quad \mid 1<q_{k} \leq 10\end{array}\right.$ & & \\
\hline$\delta_{2}\left(q_{k}\right)$ & $\begin{array}{l}\text { Customer order distribution based on } \mu_{s} \text { for single-item orders and based } 1-\mu_{s} \text { for } \\
\text { multi-orders }\left(2 \leq q_{k} \leq 10\right) \text { exponentially declining by } 2 \text { for each } k \text { in } q_{k} \\
\delta_{2}\left(q_{k}\right)=\left\{\begin{array}{l}n_{\text {del }} \mu_{s}, \quad \mid q_{k}=1 \\
n_{\text {del }}\left(1-\mu_{s}\right) / 2, \quad \mid q_{k}=2 \\
\delta_{2}\left(q_{k-1}\right) / 2, \quad \mid 3 \leq q_{k} \leq 10\end{array}\right.\end{array}$ & - & \\
\hline$\delta_{3}\left(q_{k}\right)$ & $\begin{array}{l}\text { Customer order distribution based on } \mu_{s} \text { for single-item orders and based } 1-\mu_{s} \text { for } \\
\text { multi-orders }\left(2 \leq q_{k} \leq 10\right) \text { exponentially declining by } 3 \text { for each } k \text { in } q_{k} \\
\delta_{3}\left(q_{k}\right)=\left\{\begin{array}{l}n_{\text {del }} \mu_{s}, \quad \mid q_{k}=1 \\
n_{\text {del }}\left(1-\mu_{s}\right) / 3, \quad \mid q_{k}=2 \\
\delta_{3}\left(q_{k-1}\right) / 3, \quad \mid 3 \leq q_{k} \leq 10\end{array}\right.\end{array}$ & - & \\
\hline$\delta_{4}\left(q_{k}\right)$ & $\begin{array}{l}\text { Customer order distribution based on } \mu_{s} \text { for single-item orders and based } 1-\mu_{s} \text { for } \\
\text { multi-orders }\left(2 \leq q_{k} \leq 10\right) \text { exponentially declining by } 4 \text { for each } k \text { in } q_{k} \\
\delta_{4}\left(q_{k}\right)=\left\{\begin{array}{l}n_{\text {del }} \mu_{s}, \quad \mid q_{k}=1 \\
n_{\text {del }}\left(1-\mu_{s}\right) / 4, \quad \mid q_{k}=2 \\
\delta_{4}\left(q_{k-1}\right) / 4, \quad \mid 3 \leq q_{k} \leq 10\end{array}\right.\end{array}$ & - & \\
\hline$\delta_{5}\left(q_{k}\right)$ & 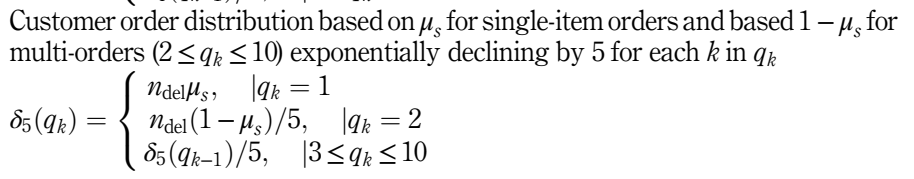 & - & Table A1. \\
\hline
\end{tabular}


IJPDLM 51,8

\section{6}

Theme Questions

Strategic questions (questions to the retailer's headquarter $(\mathrm{HQ}))$

(1) How are your retailers organized? Number of retailers, locations?

(2) What was your strategy before deciding to close many of your stores?

(3) What was the main reason for closing the stores?

(4) What have you done until now to reduce the number of returns?

(5) What logistics key performance indicators (KPIs) do you use?

(6) How are customer orders transported?

(7) What are your seasons?

(8) How do you work with ordering points if you use them?

(9) Where are the customers located?

(10) How long does it take to transport a customer's order?

Pre-ordering (questions to the retailer's $\mathrm{HQ)}$

(1) How do you group your customers? Which customer groups do you have?

(2) What customer ordering behaviors have you observed?

(3) Are returns of other products a problem for you?

(4) Have you performed any customer satisfaction surveys?

Ordering (questions to the retailer's $\mathrm{HQ}$ and warehouse)

(1) How is your assortment organized? Seasonal, basic, by sex, other?

(2) How many brands are in your assortment?

(3) Does the way you order from your suppliers differ depending on the type of product?

(4) How is the warehouse replenished?

(5) How are the stores replenished?

(6) How does a customer place an order?

(7) What is a typical customer order? Number of items, etc.

(8) How are customer orders documented? What is the level of detail in following up on the orders?

(9) How are returns documented?

(10) What is the production cost of your product?

(11) How do you place orders to replenish your products and at what times of the year?

Post-ordering (questions to the retailer's $\mathrm{HQ}$ and warehouse)

(1) What happens when a customer has reported a return and left it at a pick-up point?

(2) Which actors are part of the returns handling?

(3) What roles do these actors have?

(4) How is quality inspection done? Who inspects?

(5) Do customers typically return products in-store or at pick-up points?

(6) Are returns handled the same way for the whole assortment, or any product groups that stand out?

Scanner (questions to the retailer's HQ)

Table A2.

Interview protocol
(1) What scenarios do you see in which the scanner can be useful? (2) What processes would the scanner add in your business and what processes could it remove?

(3) What other effects could reduced returns lead to?

\section{Corresponding author}

Emmelie Gustafsson can be contacted at: emmelie.gustafsson@chalmers.se

For instructions on how to order reprints of this article, please visit our website:

www.emeraldgrouppublishing.com/licensing/reprints.htm

Or contact us for further details: permissions@emeraldinsight.com 